\title{
The effect of white sturgeon (Acipenser transmontanus) ovarian fat deposition on caviar yield and nutritional quality: introducing image processing method for sturgeon ovary fat determination
}

\author{
Mahmoudreza Ovissipour · Hamzah M. Al-Qadiri • Xiaonan Lu • \\ Yaxi Hu · Carolyn F. Ross · Joel P. Van Eenennaam · Serge I. Doroshov • \\ Barbara Rasco
}

Received: 7 March 2015/Accepted: 26 August 2015/Published online: 11 September 2015

(C) The Author(s) 2015. This article is published with open access at Springerlink.com

\begin{abstract}
Image analysis can predict the fat content of sturgeon ovaries that had been categorized as having a low, medium, and high fat content based upon the caviar yield expressed as a percent of the total ovary weight, and were correlated with the chemical measurement of total fat $\left(R^{2}=0.83\right)$. The fatty acid composition of eggs was not influenced by ovary fat content. Palmitic acid (16:00) was the most abundant saturated fatty acid and oleic acid (18:1n-9) the most predominant monounsaturated fatty acids in sturgeon eggs regardless of the ovary fat content. No significant differences $(P>0.05)$ were observed in docosahexaenoic acid (DHA) and eicosapentaenoic acid (EPA) in eggs from fish with different fat ovaries. Fourier transform infrared spectroscopy (FT-IR) coupled with principal component analysis indicated no significant difference in chemical compositions in sturgeon eggs separated from ovaries of different fat contents confirming the fatty acid composition results.
\end{abstract}

Keywords White sturgeon · Ovary fat $\cdot$ Egg quality $\cdot$ Image analysis $\cdot$ FT-IR spectroscopy

\section{Introduction}

Caviar is salt-cured and preserved eggs of one of the many sturgeon species that have been separated from the supporting connective ovarian tissue (Bledsoe et al. 2003). Caviar is a high value seafood product, and demand for caviar on domestic markets and export exceeds 2000 tons annually and has been increasing (Bledsoe et al. 2003; Ovissipour and Rasco 2012). Commercial aquaculture of sturgeons has been developed for both meat and caviar production over the past 30 years with white sturgeon (Acipenser transmontanus),

M. Ovissipour · C. F. Ross · B. Rasco ( $\square)$

School of Food Science, Washington State University, P.O. Box 646376, Pullman, WA 99164-6376, USA

e-mail: Rasco@wsu.edu

M. Ovissipour

e-mail: mrovissi@yahoo.com

H. M. Al-Qadiri

Department of Nutrition and Food Technology, Faculty of Agriculture, The University of Jordan, Amman 11942, Jordan

$\mathrm{X} . \mathrm{Lu} \cdot \mathrm{Y} . \mathrm{Hu}$

Food, Nutrition and Health Program, Faculty of Land and Food Systems, The University of British Columbia, Vancouver, BC V6T 1Z4, Canada

J. P. Van Eenennaam · S. I. Doroshov

Department of Animal Science, University of California, Davis, CA 95616, USA 
Adriatic sturgeon (A. naccarii), Siberian sturgeon (A. baerii), Russian sturgeon (A. gueldenstaedti), and beluga sturgeon (Huso huso) being among the most prominent (Ovissipour and Rasco 2011; Lu and Rasco 2013).

White sturgeon (A. transmontanus) has been commercially farmed for meat and caviar since the late $1980 \mathrm{~s}$ in California, Idaho, British Columbia (Doroshov et al. 1997; Hung et al. 1997). White sturgeon is well adapted to culture conditions, has a fast growth rate, and high quality meat and roe. Under intensive culture conditions and rearing temperatures of $18-22{ }^{\circ} \mathrm{C}$, female sturgeons first reach sexual maturity at live weights of 35-40 kg (Doroshov et al. 1997; Lu et al. 2011).

Commercial production of sturgeons can decrease pressure on wild populations, by increasing the opportunities for artificial propagation to enhance natural stocks, and producing high value meat, and caviar (Ovissipour and Rasco 2011, Ovissipour and Rasco 2012). White sturgeon males are sold for meat at age 3, 4, female fish are processed for caviar at age of 7-9 years, and the carcasses are sold for meat consumption. The prices of cultured white sturgeon caviars in USA range from $\$ 50$ to $\$ 120$ (per $30 \mathrm{~g}$ retail) depending upon the quality and market conditions.

The nutritional composition of cultured fish depends upon a number of endogenous and exogenous factors. Endogenous factors (mostly fish size) affect protein and ash, while exogenous factors (e.g., dietary lipid content and energy) dramatically affect tissue fat content (Shearer 1994). High dietary lipid results in fat deposition in the visceral cavity and tissues (Hung et al. 1997; Péres and Oliva-Teles 1999; Nanton et al. 2001). Commercial feed provides the essential nutrients required for gonadal development in female fish and the viability and quality of eggs (Santiago et al. 1983; Gunasekera et al. 1997). For white sturgeons, commercial feeds are limited and the use of salmonid feeds remains common (Hung et al. 1997). For instance, commercial salmonid diets with different energy levels (23.6-26.2 MJ/kg diet) were used for white sturgeon juveniles over an 8-week period, resulting in high lipid content in the fish (Hung et al. 1997). Ebrahimi et al. (2004) conducted a comprehensive study on the effect of different dietary lipid levels on beluga (Huso huso) fingerlings and found significantly higher fat in fish fed a high lipid diet. Lipids play an important role in fish nutrition not only as a source of energy, but also to provide essential fatty acids for the development of different tissues including gonads and eggs, and hence can influence the caviar nutritional quality (Czesny and Dabrowski 1998; Izquierdo et al. 2001). Crude lipid contents in sturgeon eggs vary from 12.5 to $27 \%$ wet weight and are high in the n-3 fatty acids, such as eicosapentaenoic (EPA) and docosahexaenoic (DHA) acids (Bledsoe et al. 2003; Gessner et al. 2002). One of the main key roles of seafood for human is the benefits of fatty acids and their beneficial effects on cardiovascular health and neurological development which could be influenced by endogenous and exogenous factors in sturgeon (Vaccaro et al. 2005; Ghomi et al. 2013).

An important quality factor is the level of lipid in the ovarian tissue. The physiological response of the sturgeons to deposit lipid in ovarian tissue is associated with dietary lipid intake, and excessive ovarian fat can reduce caviar yield, and increase processing time because of the longer screening time required to separate connective tissue from the eggs, and additional rinsing required removing adipose tissue debris.

Image processing is a useful and fast method, which can be used for sorting and grading automatization in the meat industry (Shiranita et al. 2000). Moreover, image processing for the automatization of visual inspection has gained attraction in the meat industry and many researchers have applied it in meat grading and reported it as a useful and effective tool (Shiranita et al. 2000; Maeda et al. 2014).

One of the main challenges in the sturgeon caviar processing is the fat deposition in ovary, which can cause several problems in grading, removing the eggs from the fat tissues, and quality of the final product. Grading is conducted in the field based on the visual appearance of the ovary by skill workers depend on their experience. However, automatization in sturgeon caviar facility can provide accurate and fast grading.

Therefore, the objectives of this study were to determine the effects of fat deposition in white sturgeon ovaries on caviar yield, chemical composition and fatty acid profile. An image processing technique was used to determine the ovary fat content. In addition, Fourier transform infrared spectroscopy (FT-IR) was used to determine the differences in chemical composition in eggs recovered from fish with different ovarian fat content. 


\section{Materials and methods}

Fish and sample collection

Female white sturgeons harvested for caviar were in the age range of 7-9 years from two northern California aquaculture sites (Wilton and Galt, CA, USA). Sixty ovary samples were collected throughout the processing season, on the following dates: February $2012(n=5)$, March $2012(n=12)$, April $2012(n=15)$, April $2012(n=8)$, and May $2012(n=20)$. All individual fish were weighed $( \pm 0.05 \mathrm{~kg})$ and fork length measured $( \pm 0.5 \mathrm{~cm})$. The ovaries were removed and weighed $( \pm 0.05 \mathrm{~kg})$ and a $200 \mathrm{~g}$ subsample of the ovary was collected and frozen on dry ice for image and chemical analyses. After ovary processing, the caviar yield (in the tin) was recorded $( \pm 0.1 \mathrm{~g})$. Fattiness of the ovary was categorized based upon yield of caviar from the whole ovary weight. Caviar yields of less than $50 \%$ of the ovary weight were categorized as a high fat ovary, while yields of over $65 \%$ were low fat ovaries. Yields that fell in between were categorized as medium fat ovaries. Also, this method was used to determine the yield of caviar. Ovary tissues were received on dry ice within $24 \mathrm{~h}$ by School of Food Science at Washington State University, Pullman, WA, and were immediately frozen at $-30{ }^{\circ} \mathrm{C}$ until tested.

Image analysis of ovarian tissue

Fat content in ovarian tissue was determined using image analysis (ImageJ software, National Institute of Health, USA, Version 1.47a). To determine the fat ratio in an ovary sample, photographs of individual ovaries were collected using a Canon 60D camera (Canon USA., Inc. Melville, NY, USA.) from 6 dimensions of the ovary samples and then images converted to the 8-bit pictures. For each picture, a $2 \mathrm{~cm}$ scale was used. Providing the scale during the photography is the key part of the image processing. Because according to the software instruction, specific scale should be defined for the software. These images were then converted to threshold pictures using ImageJ software (ImageJ User Guide, 2012). Threshold option converts all pictures into black and white based on the original color differences. To find the best fit model for threshold different, limits were applied to find the optimum threshold values which were 85-120. After conversion, the black color represented low fat tissues while white color denoted the visible fat tissues (Fig. 1). In this step, the specific

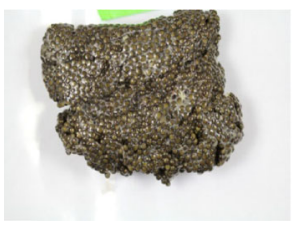

a

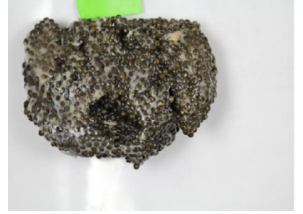

a

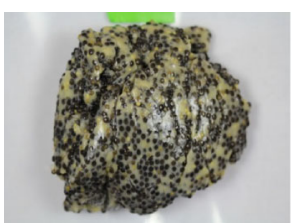

a

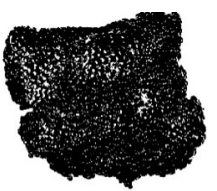

b

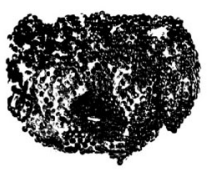

b

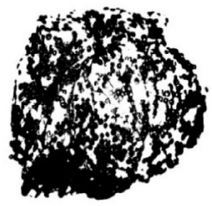

b

Fig. 1 Digital images of low, medium and high fat ovary samples, a: before processing by ImageJ, b: after processing by imageJ (threshold pictures) 
scale (which was $2 \mathrm{~cm}$ in current study) was defined for the software and, based on the defined scale, the area of white and black parts was automatically calculated by software. Then the white area which was representing the fat content was measured and the ratio of the white area to total area was presented as fat content.

Fat content and fatty acid analysis by gas chromatography

To determine the fat content of fish ovaries, the lipid in the ovaries was extracted according to the method by Bligh and Dyer (1959) with a slight modification. Briefly, $10 \mathrm{~g}$ of sturgeon ovary was mixed with $10 \mathrm{~mL}$ distilled water, $20 \mathrm{~mL}$ chloroform and $40 \mathrm{~mL}$ methanol, homogenized then sonicated for $2 \mathrm{~min}$ in iced water for better separation using an ultrasound bath $\left(100 \mathrm{~W}, 40 \mathrm{kHz}\right.$, Bransonic ${ }^{\circledR}$, Process Equipment and Supply, Inc. Cleveland, $\mathrm{OH})$. Then the samples were kept at $4{ }^{\circ} \mathrm{C}$ for overnight in glass tubes. Samples were centrifuged for $10 \mathrm{~min}$ at $3000 \times \mathrm{g}$ at $4{ }^{\circ} \mathrm{C}$. The chloroform part was separated and transferred to a glass tube and kept at $40{ }^{\circ} \mathrm{C}$ to evaporate the solvent. At the end, to completely remove the solvent, nitrogen gas was injected to samples and then the fat content was calculated based on the weight of the sample, and the fat which was obtained.

To determine the fatty acid composition in eggs, eggs were first separated from ovary tissues and then the egg lipid was extracted as described above. Fatty acid composition was determined as described by Watts and Browse (2002) with minor modification. Briefly, $50 \mu \mathrm{L}$ of egg lipid extract was mixed with $450 \mu \mathrm{L}$ hexane. Then, $10 \mu \mathrm{L}$ of the mixture was added to a small screw-cap glass tube. Fatty acids were derivatized to methyl esters by adding $2.5 \% \mathrm{H}_{2} \mathrm{SO}_{4}$ in $\mathrm{MeOH}$ followed by heating at $80{ }^{\circ} \mathrm{C}$ for $30 \mathrm{~min}$. After cooling to room temperature (i.e., $22{ }^{\circ} \mathrm{C}$ ), $500 \mu \mathrm{L}$ hexane and $1.5 \mathrm{~mL} \mathrm{H}_{2} \mathrm{O}$ were added and the mixture shaken vigorously. Following low speed centrifugation $(1000 \times g$ for $1 \mathrm{~min})$, two phases were clearly separated. Then, $70 \mu \mathrm{L}$ of top layer was loaded into a vial and injected into gas chromatography (GC). Methyl esters were analyzed by GC using an Agilent 6890 series gas chromatograph equipped with $30 \mathrm{~m} \times 0.32 \mathrm{~mm}$ Omegawax $^{\mathrm{TM}} 320$ capillary column (Supelco ${ }^{\mathrm{TM}}$, Sigma Aldrich, St. Louis, MO, USA), helium as the carrier gas at $1.4 \mathrm{~mL} / \mathrm{min}$, and a flame ionization detector. To quantify the fatty acids, internal standard (C17:0-Methyl-Ester, $10 \mu \mathrm{g}$ for $200 \mathrm{mg}$ of lipids) was added to each sample, while an external standard (Natural Menhaden oil; Matreya LLC, Pleasant Gap, PA, USA) was run as an external standard. The GC was programmed for an initial temperature of $120{ }^{\circ} \mathrm{C}$ for $1 \mathrm{~min}$ followed by an increase of $10^{\circ} \mathrm{C} / \mathrm{min}$ to $190{ }^{\circ} \mathrm{C}$ followed by an increase of $2{ }^{\circ} \mathrm{C} / \mathrm{min}$ to $200{ }^{\circ} \mathrm{C}$.

FT-IR spectroscopy and spectra collection

FT-IR spectral features of eggs separated from each individual sturgeon ovary were collected using Thermo Nicolet Avatar 360 FT-IR spectrometer (Thermo Electron Inc., San Jose, CA, USA). A sturgeon egg was put in direct contact with the attenuated total reflectance (ATR) ZnSe crystal cell (Lu et al. 2011). Eighteen spectra were collected at $22{ }^{\circ} \mathrm{C}$ for each sample at different locations on the surface of the egg.

Chemometrics and statistical analysis

To determine the influence of ovary fat on the quality of eggs, one way analysis of variance (ANOVA) (Duncan multiple test) using SPSS software, release 16.0 (SPSS Inc., Chicago, IL, USA.) at a probability level of $P<0.05$ was used.

FT-IR spectral analyses were conducted using OMNIC (Thermo Electron Inc.) and Matlab (The MathWorks, Inc. Natick, MA, USA.). Data pre-processing algorithms, including baseline correction and normalization, were performed. Binning $\left(2 \mathrm{~cm}^{-1}\right)$ and smoothing (Gaussian function over $\left.10 \mathrm{~cm}^{-1}\right)$ were conducted to reduce spectral noises. After spectral processing, principal component analysis (PCA) was developed using the wavenumbers of $4000-550 \mathrm{~cm}^{-1}$ according to Lu et al. (2010). 


\section{Results and discussion}

Chemical and image analysis of sturgeon ovary

Fat content determined by chemical and image analysis are shown in Table 1 . The highest $(28.7 \pm 11.50 \%)$ and lowest fat $(19.85 \pm 12.71 \%)$ contents determined by image analysis were from fish that were categorized as high fat and low fat, respectively. Ovaries had highly variable amounts of adipose fat and fat interspersed between eggs in the ovarian tissue. The first step of image analysis was to examine the photographs of sturgeon ovaries in a visual determination as to whether an ovary has high, medium or low fat. Photographs from different sides of the ovaries were taken and processed by image processing software, and the results are the mean of different sides of a sample.

Chemical analysis showed significant differences $(P<0.05)$ between high fat ovary and low fat ovary. However, no significant differences were observed $(P>0.05)$ between high fat and medium fat samples, and low fat and medium fat samples.

The correlation between fat content determined by chemical analysis and image analysis is shown in Fig. 2 . There was a high correlation coefficient between chemical measurements and image analysis $\left(R^{2}=0.83\right)$ even though the image was from the ovary surface only and did not reflect the differences in lipid content from the surface to the interior of the ovarian mass or from the dorsal to the abdominal surface. Therefore, image analysis may be a useful, fast and inexpensive tool for sturgeon aquaculture sectors to predict the ovary fat content and sort the fish accordingly. Image analysis is one of the suitable tools that can be used to determine the quality of different food products. Many researchers have used image analysis techniques to predict the fat content of beef meat (Kuchida et al. 2000; Shiranita et al. 2000; Chambaz et al. 2003; Nakahashi et al. 2008; Maeda et al. 2014). According to the current study, image analysis could be introduced for grading and sorting of sturgeon ovary at the farms. However, further studies are required for quality grading of sturgeon ovary images from different sections of ovaries.

One of the most important influences of the ovary fat content is the effect on egg yield (\%BW and OW). The results of ovary weight, egg weight and egg yield (\%BW and OW) are presented in Table 2. Eggs yield $(\% \mathrm{BW}$ and $\mathrm{OW})$ results showed significant differences $(P<0.05)$ between low fat ovary and medium and high fat ovaries. The egg yield (\%OW) was $75.4 \%$ in low fat ovary compared to $38.7 \%$ in high fat ovary.

Table 1 Fat content in sturgeon ovaries determined by chemical and image analysis

\begin{tabular}{llcc}
\hline Sample & Chemical analysis $(\%)$ & Image analysis $(\%)$ & Number of samples \\
\hline Low fat & $28.24 \pm 10.57^{\mathrm{a}}$ & $19.85 \pm 12.71^{\mathrm{a}}$ & 22 \\
Medium fat & $32.63 \pm 8.71^{\mathrm{ab}}$ & $25.03 \pm 12.45^{\mathrm{ab}}$ & 18 \\
High fat & $37.52 \pm 9.1^{\mathrm{b}}$ & $28.7 \pm 11.50^{\mathrm{b}}$ & 20 \\
\hline
\end{tabular}

Values in column with different superscripts are significantly different at $\alpha=0.05$

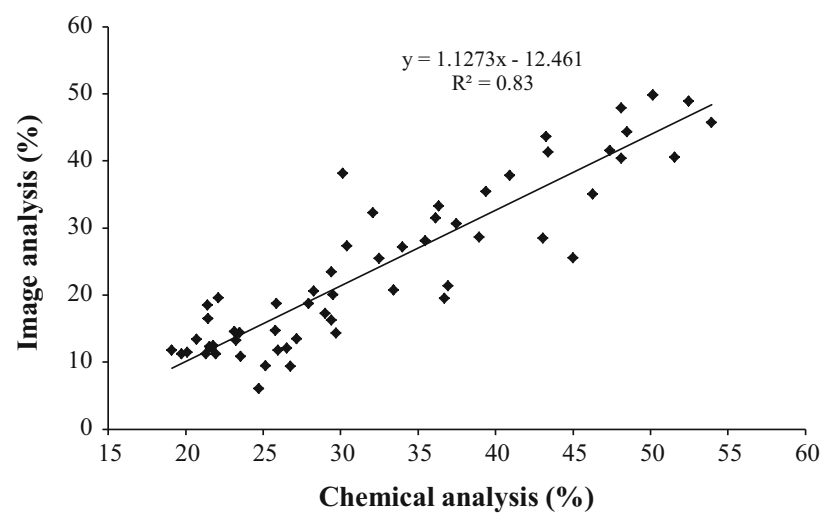

Fig. 2 Correlation between chemical and image analysis for fat content in sturgeon ovaries 
Table 2 Sturgeon ovary and egg quality parameters

\begin{tabular}{lcccccc}
\hline & Body weight $(\mathrm{kg})$ & Ovary weight $(\mathrm{kg})$ & Egg weight $(\mathrm{g})$ & Egg yield $(\% \mathrm{BW})$ & Egg yield $(\%$ OW) & GSI \\
\hline Low fat & $35.11 \pm 7.6^{\mathrm{a}}$ & $4.3 \pm 1.2^{\mathrm{a}}$ & $3251 \pm 900^{\mathrm{a}}$ & $9.22 \pm 0.8^{\mathrm{a}}$ & $75.33 \pm 2^{\mathrm{a}}$ & $12.22 \pm 0.88^{\mathrm{a}}$ \\
Medium fat & $40.14 \pm 11.8^{\mathrm{a}}$ & $5.5 \pm 2^{\mathrm{a}}$ & $3136 \pm 800^{\mathrm{a}}$ & $8.20 \pm 0.4^{\mathrm{b}}$ & $60.34 \pm 1.6^{\mathrm{b}}$ & $13.59 \pm 0.6^{\mathrm{a}}$ \\
High fat & $47 \pm 9^{\mathrm{a}}$ & $7 \pm 2.4^{\mathrm{a}}$ & $2677 \pm 738^{\mathrm{a}}$ & $5.3 \pm 0.4^{\mathrm{b}}$ & $38.74 \pm 4^{\mathrm{c}}$ & $14.44 \pm 2^{\mathrm{a}}$ \\
\hline
\end{tabular}

Values in column with different superscripts are significantly different at $\alpha=0.05$

Generally, sturgeons are cultured for both meat and caviar production and an excessively fat content in the ovary would result in reduced feed conversion increasing production costs (Ovissipour and Rasco 2011). One of the major issues in female sturgeon is lipid deposition in the ovary which can decrease egg yield. In addition, this fatty tissue negatively influences caviar processing by slowing down the processing because it requires more rinsing and cleaning of eggs prior to salting and curing, compared to a lean ovary. Taken together, our current study indicated that a higher egg yield can be achieved with lower fat in the ovary.

Fatty acid composition of sturgeon eggs

Fatty acid composition of eggs separated from fish that were categorized as having low, medium and high fat ovaries is shown in Table 3. In all of the groups, palmitic acid (16:00) was the most abundant saturated fatty acid (SAFA) regardless of the ovary lipid content. Palmitic acid tends to be the predominant saturated fatty acid in cultivated sturgeons (Chen et al. 1995; Ovissipour and Rasco 2011). Oleic acid (18:1n-9) was the most predominant monounsaturated fatty acid (MUFA) as reported by others for the study of eggs and tissues from sturgeon and other fish (Ashton et al. 1993; Gallagher et al. 1998; Czesny et al. 2000; Vaccaro et al. 2005; Caprino et al. 2008; Mol and Turan 2008; Ovissipour and Rasco 2011). No significant differences $(P<0.05)$ were observed in docosahexaenoic acid (DHA) and eicosapentaenoic acid (EPA) among the ovaries in fish. The percentages of EPA and DHA were similar regardless of ovary fat levels, indicating that the optimal threshold levels had been reached. Similar results were found by other researchers for domesticated walleye (Stizostedion vitreum) (Czesny and Dabrowski 1998), Atlantic halibut (Hippoglossus hippoglossus) (Mazorra et al. 2008) and white sturgeon (A. transmontanus) (Caprino et al. 2008).

The ratio of n-3 to n-6 PUFA ranged from 2.7 to 3.65, which are within the typical range for freshwater fish eggs (0.5-3.8) (Caprino et al. 2008). No significant difference was observed $(P<0.05)$ in n-3, n-6 and n-3 to $\mathrm{n}-6$ between different ovary groups for the fish in the current study.

\section{FT-IR spectral features of sturgeon eggs}

FT-IR spectroscopy is a type of vibrational spectroscopy and has been widely applied to determine the biochemical compositions of biological and agricultural systems, such as proteins, lipids, nucleic acids and carbohydrates moieties (Al-Holy et al. 2006; Burgula et al. 2007). Recently, FT-IR spectroscopy was applied in aquaculture to investigate the chemical components in white sturgeon female plasma, leading to a rapid and less-invasive determination of fish maturity Lu et al. (2010, 2013).

FT-IR spectral features of separated eggs from fish with low, medium and high levels of ovarian fat were determined and there was no obvious difference in egg composition (Fig. 3). The peaks around 3010 (Olefinic $=\mathrm{CH}$ stretching vibration: lipids, cholesterol esters $), 2922\left(\mathrm{CH}_{2}\right.$ asymmetric stretch of methylene groups: mainly lipids), $2852\left(\mathrm{CH}_{2}\right.$ symmetric stretch of methylene groups: mainly lipids), 1743 ( $\mathrm{C}=\mathrm{O}$ of ester functional groups: triglycerides, cholesterol esters), and $1458\left(\mathrm{CH}_{2}\right.$ bending: mainly lipids, with little contribution from proteins) are assigned as stretching, vibration or bending of molecular bonds in lipid molecules showing that the surface of eggs is rich in lipid and there is no significant difference among eggs taken from ovaries with high or low fat content. FT-IR spectral feature of white sturgeon eggs is very highly conserved and does not appear to be affected by maturity stage of the fish (Lu et al. 2011). An unsupervised PCA model was developed to differentiate sturgeon eggs separated from ovaries with different fat content (i.e., low, medium and high fats), but no clear segregation could be obtained (Fig. 4) indicating that the 
Table 3 Fatty acid composition of eggs recovered from low, medium, and high fat ovaries

\begin{tabular}{|c|c|c|c|}
\hline Fatty acid (\%wt) & $\begin{array}{l}\text { Low fat ovary }(N=22) \\
\text { Mean } \pm \mathrm{SD}\end{array}$ & $\begin{array}{l}\text { Medium fat ovary }(N=18) \\
\text { Mean } \pm \text { SD }\end{array}$ & $\begin{array}{l}\text { High fat ovary }(N=20) \\
\text { Mean } \pm \text { SD }\end{array}$ \\
\hline $\mathrm{C} 14: 0$ & $1.74 \pm 0.37$ & $1.79 \pm 0.08$ & $2.43 \pm 0.46$ \\
\hline $\mathrm{C} 16: 0$ & $18.39 \pm 0.34$ & $18.01 \pm 0.52$ & $18.02 \pm 0.43$ \\
\hline $\mathrm{C} 16: 1 \mathrm{n} 7$ & $5.16 \pm 0.42$ & $5.24 \pm 0.35$ & $5.75 \pm 0.33$ \\
\hline $\mathrm{C} 16: 2 \mathrm{n} 4$ & $0.17 \pm 0.06$ & $0.14 \pm 0.03$ & $0.27 \pm 0.05$ \\
\hline $\mathrm{C} 16: 3 \mathrm{n} 4$ & $7.28 \pm 0.55$ & $7.06 \pm 0.57$ & $6.09 \pm 0.23$ \\
\hline $\mathrm{C} 16: 4 \mathrm{n} 1$ & $0.17 \pm 0.06$ & $0.14 \pm 0.03$ & $0.27 \pm 0.05$ \\
\hline $\mathrm{C} 18: 0$ & $3.19 \pm 0.09$ & $3.05 \pm 0.04$ & $2.54 \pm 0.15$ \\
\hline $\mathrm{C} 18: \ln 9$ & $32 \pm 4.53$ & $34.96 \pm 1.54$ & $35.10 \pm 2.34$ \\
\hline $\mathrm{C} 18: 1 \mathrm{n} 7$ & $0.17 \pm 0.06$ & $0.14 \pm 0.03$ & $0.27 \pm 0.05$ \\
\hline $\mathrm{C} 18: 2 \mathrm{n} 6$ & $6.49 \pm 1.25$ & $7.34 \pm 0.63$ & $6.75 \pm 1.13$ \\
\hline $\mathrm{C} 18: 2 \mathrm{n} 4$ & $0.17 \pm 0.06$ & $0.14 \pm 0.03$ & $0.27 \pm 0.05$ \\
\hline $\mathrm{C} 18: 3 \mathrm{n} 4$ & $0.36 \pm 0.11$ & $0.29 \pm 0.04$ & $0.36 \pm 0.08$ \\
\hline $\mathrm{C} 18: 3 \mathrm{n} 3$ & $1.02 \pm 0.43$ & $0.95 \pm 0.35$ & $1.14 \pm 0.61$ \\
\hline $\mathrm{C} 18: 4 \mathrm{n} 3$ & $0.38 \pm 0.09$ & $0.32 \pm 0.06$ & $0.49 \pm 0.06$ \\
\hline $\mathrm{C} 20: \ln 9$ & $1.37 \pm 0.27$ & $1.52 \pm 0.38$ & $1.79 \pm 0.41$ \\
\hline C20:4n6 (AA) & $0.17 \pm 0.06$ & $0.14 \pm 0.03$ & $0.27 \pm 0.05$ \\
\hline $\mathrm{C} 20: 4 \mathrm{n} 3$ & $2.41 \pm 0.18$ & $2.26 \pm 0.12$ & $1.81 \pm 0.12$ \\
\hline C20:5n3 (EPA) & $0.39 \pm 0.17$ & $0.34 \pm 0.03$ & $0.46 \pm 0.11$ \\
\hline $\mathrm{C} 21: 5 \mathrm{n} 3$ & $5.28 \pm 1.34$ & $4.50 \pm 0.28$ & $5.00 \pm 0.75$ \\
\hline C22:5n3 (DPA) & $1.89 \pm 0.63$ & $1.64 \pm 0.05$ & $1.83 \pm 0.34$ \\
\hline C22:6n3 (DHA) & $11.82 \pm 2.00$ & $9.95 \pm 0.13$ & $9.04 \pm 1.46$ \\
\hline$\sum \mathrm{SAFA}$ & $23.30 \pm 0.83$ & $22.84 \pm 0.58$ & $22.99 \pm 0.55$ \\
\hline$\sum$ MUFA & $38.67 \pm 4.29$ & $41.88 \pm 1.36$ & $42.91 \pm 2.12$ \\
\hline$\sum n-3$ & $23.18 \pm 3.94$ & $19.99 \pm 0.9$ & $19.79 \pm 2.7$ \\
\hline$\sum n-6$ & $6.7 \pm 1.20$ & $7.48 \pm 0.65$ & $7.02 \pm 1.08$ \\
\hline$n-3 / n-6$ & $3.64 \pm 1.20$ & $2.70 \pm 0.34$ & $2.90 \pm 0.85$ \\
\hline
\end{tabular}

Low fat sample $a b$

Medium fat sample $a b$

High fat sample $a b$

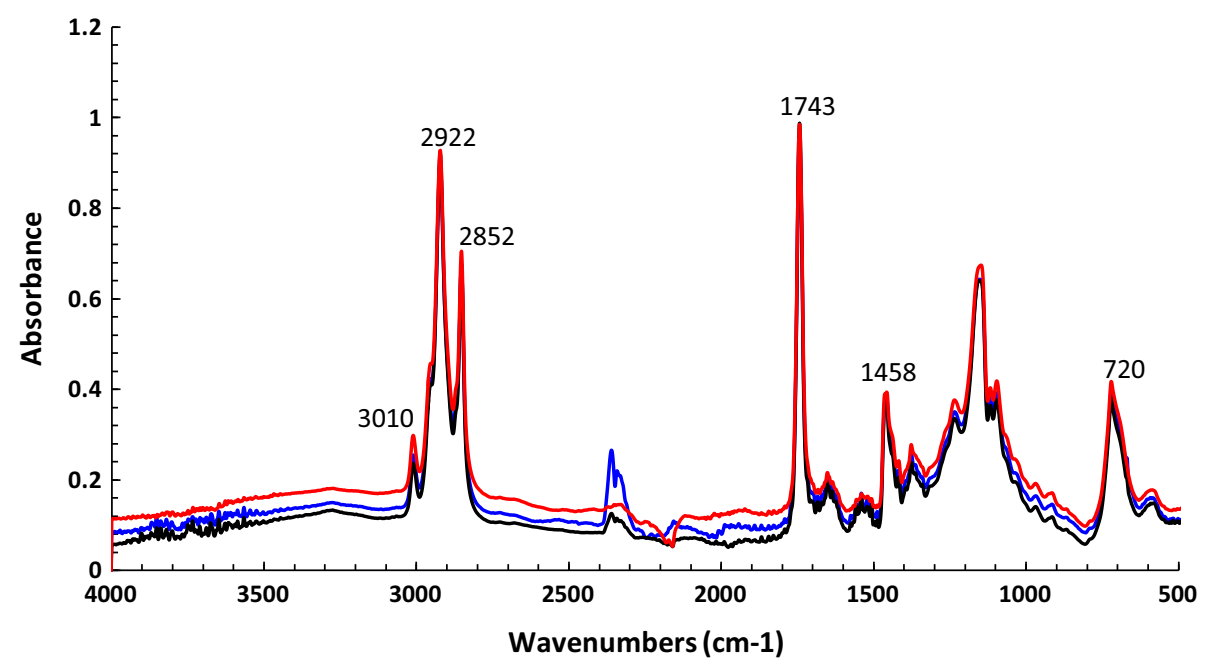

Fig. 3 FT-IR spectrum of white sturgeon eggs (red: low fat; black: medium fat; blue: high fat) $(n=60)$ 


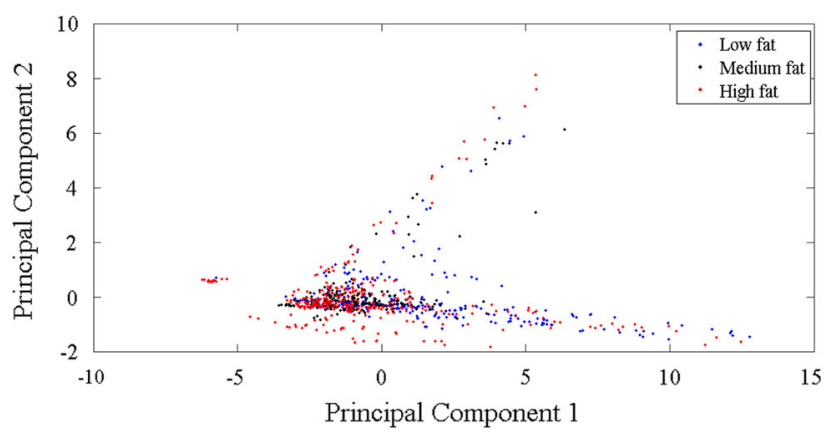

Fig. 4 Principal component analysis (PCA) of sturgeon eggs separated from ovarian samples with different levels of fat. Principal Component (PC) 1 explained $69.9 \%$ of the variance, while PC2 explained $11.61 \%$ of the variance $(n=60)$

composition of sturgeon eggs was not affected by the fat content in the ovarian tissues. Raman spectroscopy has recently been applied to determine the quality of different caviars from Caspian Sea (Mohamadi Monavar et al. 2013). They indicated that Raman spectroscopy coupled with partial least squares regression models could be used to characterize fatty acid features of different species of sturgeon.

\section{Conclusion}

We used image analysis as a rapid method to determine the fat content of different ovaries. Image analysis method was correlated with the conventional Bligh and Dyer chemical extraction method for total fat $\left(R^{2}=0.83\right)$. Fatty acid composition was not significantly different in eggs from low, medium and high fat ovaries. In addition, by applying FT-IR, no significant differences among fish with different ovary fat contents in protein or lipid content were observed. The current study showed that the fat content in ovary can influence the egg yield, and ovary weight, but had little influence on the macronutrient properties of the caviar.

Acknowledgments This study was funded by Western Region Aquaculture Center, U.S. Department of Agriculture, under grant number 2007-38500-18593. We would like to express our sincere thanks to Professor John A. Browse and Dr. James G. Wallis in the Institute of Biological Chemistry at WSU and for sturgeon farmers across the Western region for their technical assistance and support of this research.

\section{Compliance with ethical standards}

Conflict of interest The authors declare no competing financial interest.

Funding This study was funded by Western Region Aquaculture Center, U.S. Department of Agriculture, under grant number 2007-38500-18593.

Authors' contributions MO conducted the experiment and developed the image analysis protocol for sturgeon ovary fat determination. HA provided technical supports for FT-IR spectra collecting. XL provided technical supports for FT-IR spectra statistical analysis. YH provided technical supports for FT-IR spectra statistical analysis. CR Scientifically supported the project. JVE and SD from UC Davis conducted sturgeon aquaculture trials. BR supported the whole experiment scientifically and technically.

Open Access This article is distributed under the terms of the Creative Commons Attribution 4.0 International License (http:// creativecommons.org/licenses/by/4.0/), which permits unrestricted use, distribution, and reproduction in any medium, provided you give appropriate credit to the original author(s) and the source, provide a link to the Creative Commons license, and indicate if changes were made.

\section{References}

Al-Holy MA, Lin M, Cavinato AG, Rasco B (2006) The use of Fourier transform infrared spectroscopy to differentiate Escherichia coli O157:H7 from other bacteria inoculated into apple juice. Food Microbiol 23(2):162-168 
Ashton HJ, Farkvan DO, March BE (1993) Fatty acid composition of lipids in the eggs and alevins from wild and cultured chinook salmon (Oncorhynchus tshawytscha). Can J Fish Aquatic Sci 50(3):648-655

Bledsoe GE, Bledsoe CD, Rasco B (2003) Caviars and fish roe products. Crit Rev Food Sci Nutr 43(3):317-356

Bligh EG, Dyer WJA (1959) A rapid method for total lipid extraction and purification. Can J Biochem. Physiol 37(8):911-917

Burgula Y, Khali D, Kim S, Krishnan SS, Cousin MA, Gore JP, Reuhs BL, Mauer LJ (2007) Review of mid-infrared Fourier transform infrared spectroscopy applications for bacterial detection. J Rapid Methods Auto Microbiol 15(2):146-175

Caprino F, Moretti VM, Bellagamba F, Turchini GM, Busetto ML, Giani I, Paleari MA, Pazzaglia M (2008) Fatty acid composition and volatile compounds of caviar from farmed white sturgeon (Acipenser transmontanus). Anal Chim Acta 617(1-2):139-147

Chambaz A, Scheeder MRL, Kreuzer M, Dufey PA (2003) Meat quality of Angus, Simmentral, Charolais and Limousin steers compared at the same intramuscular fat content. Meat Sci 63(4):491-500

Chen IC, Chapman FA, Wei CI, Portier KM, O'Keefe SFJ (1995) Differentiation of cultured and wild sturgeon (Acipenser oxyrinchus desotoi) based on fatty acid composition. J Food Sci 60(3):631-635

Czesny S, Dabrowski K (1998) The effect of egg fatty acid concentrations on embryo viability in wild and domesticated walleye (Stizostedion vitreum). Aquat Living Res 11(6):371-378

Czesny S, Dabrowski K, Christensen JE, Van Eenennaam JP, Doroshov SI (2000) Discrimination of wild and domestic origin of sturgeon ova based on lipids and fatty acid analysis. Aquaculture 189(1-2):145-153

Doroshov SI, Moberg GP, Van Eenennaam JP (1997) Observations on the reproductive cycles of cultured white sturgeon, Acipenser transmontanus. Environ Biol Fishes 48:265-278

Ebrahimi E, Pourreza J, Panamariov SV, Kamali A, Hosaini A (2004) Effect of different levels of protein and fat on growth characters and chemical composition of fingerling beluga (Huso huso L.). J Sci Technol Agric Nat Res 2:229-241 (In Persian, Abstract in English)

Gallagher ML, Paramore L, Alves D, Rulifson RA (1998) Comparison of phospholipid and fatty acid composition of wild and cultured striped bass eggs. J Fish Biol 52(6):1218-1228

Gessner J, Wirth M, Kirschbaum F, Kruger A, Patriche N (2002) Caviar composition in wild and cultured sturgeons-impact of food sources on fatty acid composition and contaminant load. J Appl Ichthyol 18(4-6):665-672

Ghomi MR, Nikoo M, Sohrabnejad M (2013) Effect of alive weight on body composition and fatty acid content of farmed beluga sturgeon (Huso huso). Intel Aqua Res 5:6

Gunasekera RM, Shim KF, Lam TJ (1997) Influence of dietary protein content on the distribution of amino acids in oocytes, serum and muscle of Nile tilapia, Oreochromis niloticus (L.). Aquaculture 152(1-4):205-221

Hung SSO, Storebakken T, Cui Y, Tian L, Einen O (1997) High-energy diets for white sturgeon, Acipenser transmontanus Richardson. Aquac Nutr 3(4):281-286

Izquierdo MS, Fernández-Palacios H, Tacon AGJ (2001) Effect of broodstock nutrition on reproductive performance of fish. Aquaculture 197(1-4):25-42

Kuchida A, Kono S, Konishi K, Van Vleck LD, Suzuki M, Miyoshi S (2000) Prediction of crude fat content of longissimus muscle of beef using the ratio of fat area calculated from computer image analysis: Comparison of regression equations for prediction using different input devices at different stations. J Anim Sci 78(4):799-803

Lu X, Rasco B (2013) Sturgeon (Acipenser transmontanus) sexual maturation and caviar quality. Rev Aquac 6(2):89-99

Lu X, Webb MAH, Talbott MJ, Van Eenennaam JP, Palumbo A, Linares-Casenave J, Doroshov SI, Struffenegger P, Rasco B (2010) Distinguishing ovarian maturity of farmed white sturgeon (Acipenser transmontanus) by Fourier transform infrared spectroscopy: a potential tool for caviar production management. J Agric Food Chem 58(7):4056-4064

Lu X, Webb MAH, Talbott MJ, Van Eenennaam JP, Doroshov SI, Rasco B (2011) A study of biochemical parameters associated with ovarian atresia and quality of caviar in farmed white sturgeon (Acipenser transmontanus) by Fourier Transform Infrared (FT-IR) Spectroscopy. Aquaculture 315(3-4):298-305

Lu X, Talbot MJ, Van Eenennaam JP, Webb MAH, Doroshov SI, Ovissipour M, Rasco B (2013) Determining ovarian maturity in farmed sturgeon (Acipenser transmontanus) for caviar production using Fourier transform infrared spectroscopy (FT-IR). J Aquac Res Dev 5:1. doi:10.4172/2155-9546.1000202

Maeda S, Grose J, Kato K, Kuchida K (2014) Comparing AUS-MEAT marbling scores using image analysis traits to estimate genetic parameters for marbling of Japanese Black cattle in Australia. Animal Prod Sci 54(5):557-563

Mazorra C, Bruce M, Bell JG, Davie A, Alorrend E, Jordan N, Rees J, Papanikos N, Porter M, Bromage N (2003) Dietary lipid enhancement of broodstock reproductive performance and egg and larval quality in Atlantic halibut (Hippoglossus hippoglossus). Aquaculture 227(1-4):21-33

Mohamadi Monavar H, Afseth N, Lozano J, Alimardani R, Omid M, Wold J (2013) Determining quality of caviar from Caspian Sea based on Raman spectroscopy and using artificial neural networks. Talanta 111:98-104

Mol S, Turan S (2008) Comparison of proximate, fatty acid and amino acid compositions of various types of fish roes. Int J Food Prop 11(3):669-677

Nakahashi Y, Maruyama S, Seki S, Hidaka S, Kuchida K (2008) Relationships between monounsaturated fatty acids of marbling flecks and image analysis traits in longissimus muscle for Japanese Black steers. J Anim Sci 86(12):3551-3556

Nanton DA, Lall SP, McNiven MA (2001) Effects of dietary lipid level on liver and muscle lipid deposition in juvenile haddock, Melanogrammus aeglefinus L. Aquac. Res 32(s1):225-234

Ovissipour M, Rasco B (2011) Fatty acid and amino acid profiles of domestic and wild beluga (Huso huso) roe and impact on fertilization ratio. J Aquac Res Develop. doi:10.4172/2155-9546.1000113

Ovissipour M, Rasco B (2012) Sturgeon: Conservation of Caspian Sea Stocks. J Aquac Res Develop. doi:10.4172/2155-9546. $1000 \mathrm{e} 104$

Péres H, Oliva-Teles A (1999) Effect of dietary lipid level on growth performance and feed utilization by European seabass juveniles Dicentrarchus labrax. Aquac. 179(1-4):325-334 
Santiago CB, Aldaba MB, Laron MA (1983) Effect of varying dietary crude protein levels on spawning frequency and growth of Sarotherodon niloticus breeders. Fish Res J Phil 8(2):9-18

Shearer KD (1994) Factors affecting the proximate composition of cultured fishes with emphasis on salmonids. Aquac. 119(1):63-88

Shiranita K, Hayashi K, Otsubo A, Miyajima T, Takiyama R (2000) Grading meat quality by image processing. Pattern Reco 33(1):97-104

Vaccaro AM, Buffa G, Messina M, Santulli A, Mazzola A (2005) Fatty acid composition of a cultured sturgeon hybrid (Acipenser naccarii $\times$ A. baerii). Food Chem 93(4):627-631

Watts JL, Browse J (2002) Genetic dissection of polyunsaturated fatty acid synthesis in Caenorhabditis elegans. Proc Natl Acad Sci 99(9):5854-5859 